\title{
Sex Differences in Amphetamine-Elicited Rotational Behavior and the Lateralization of Striatal Dopamine in Rats ${ }^{1}$
}

\author{
TERRY E. ROBINSON \\ Psychology Department and Neuroscience Laboratory, University of Michigan, Ann Arbor, MI \\ AND \\ JILL B. BECKER ${ }^{2}$ AND V. D. RAMIREZ \\ Neural and Behavioral Biology Program and \\ Departments of Physiology and Biophysics, University of Illinois, Champaign, IL
}

Received 16 January 1980

\begin{abstract}
ROBINSON, T. E., J. B. BECKER AND V. D. RAMIREZ. Sex differences in amphetamine-elicited rotational behavior and the lateralization of striatal dopamine in rats. BRAIN RES. BULL. 5(5) 539-545, 1980.-Sex differences are described in both a lateralized behavior (amphetamine-elicited rotation) and in the lateralization of striatal dopamine (DA) content. Amphetamine (AMPH) elicited significantly more partial turns, total rotations and lateralized (net) rotations in female, than in male rats. The two sexes also differed in their pattern of net rotations over time. In females, but not males, the striatum containing higher DA levels after amphetamine was consistently found to be contralateral to the dominant direction of rotation observed in the first $5 \mathrm{~min}$ interval after AMPH. No relationship was found between rotational behavior and medial frontal cortex DA or norepinephrine. The results are discussed in reference to cerebral lateralization in humans, and to possible sex differences in the modulatory effects of gonadal steroid hormones on striatal function.
\end{abstract}

$\begin{array}{lcccc}\text { Sex differences } & \text { Amphetamine } \\ \text { Lateralization } & \text { Gonadal steroids } & \begin{array}{c}\text { Asymmetry Dopamine } \\ \text { Catecholamines }\end{array} & \text { Striatum } & \text { Rotational behavior }\end{array}$

SEX differences in a wide variety of behaviors have been documented in a great many species $[2,3,9,27,28,37,42$, $43,46,52,53,57,59]$. Many of these sex differences in behavior have been attributed to either the early organizational effects of gonadal steroid hormones on the central nervous system, or to their activational role in the adult animal $[3,27,28,55]$. An obvious question which arises from these observations is, with what brain structures do gonadal steroids interact to result in behavioral sex differences? Considerable progress has been made towards answering this question with respect to sex differences in reproductive behaviors. For example, sex differences have been described in hypothalamic-preoptic area anatomy and function $[18,26,27,30,54]$ that are believed to underlie sex differences in gonadotrophin release and reproductive behaviors. However, there is very little evidence available as to whether gonadal steroids interact with extra-hypothalamic neural systems to result in sexually dimorphic nonreproductive behaviors.

In the initial attempt to study sex differences in non- reproductive behaviors reported here, we first identified a neural system outside the hypothalamo-pituitary axis which may be sexually dimorphic. There is considerable evidence to suggest that gonadal steroids interact with hypothalamic catecholamine (CA) systems [22]. Therefore, one logical place to suspect sexual dimorphism would be in other brain CA systems. Indeed, a review of the literature shows that the nigrostriatal dopamine (DA) system may be sexually dimorphic. In recent studies Becker and Ramirez [5] demonstrated that the in vivo presence or absence of gonadal steroids modulates the amphetamine-stimulated in vitro release of DA from striatal tissue fragments obtained from female, but not male, rats. Sex differences have been reported in striatal DA content [14], and in female rats or mice the concentration and turnover of striatal DA fluctuates across the estrous cycle [15,34]. Also gonadal steroid modulation of striatal activity is suggested by reports that estrogen influences circling (rotational) and stereotyped behaviors induced by dopaminergic agonists $([7,11,33,39,50,51]$; see below).

We hypothesized that if sex differences exist in the in

'Research supported by Grants 136115 from the DRDA of the University of Michigan to T. E. R., NSF PCM 77-04656 to V. D. R. and NSR-SER 76-18255 to the University of Illinois. We thank W. Greenough, B. Kolb, J. McGlone and E. S. Valenstein for helpful comments, and Judith Lehman for typing the manuscript. Reprint requests to Dr. T. E. Robinson, Neuroscience Laboratory Bldg., 1103 E. Huron, Ann Arbor, MI 48109.

${ }^{2}$ Present address: Neuroscience Laboratory Bldg., 1103 E. Huron, Ann Arbor, MI 48109. 
vitro release of striatal DA [5], such differences should be evident in behaviors thought to involve nigrostriatal activity. There is a good deal of evidence that amphetamine (AMPH)-induced rotational behavior in both unilaterally lesioned and intact rodents involves the asymmetric release of DA from nigrostriatal neurons $[24,49,58]$. In the experiments reported here we looked for sex differences in AMPHelicited rotational behavior in intact (non-lesioned) rats because: (1) The evidence that rotational behavior in intact rats is a reasonably sensitive 'behavioral assay' of nigrostriatal DA activity seems quite strong [24]; (2) It is an easily quantifiable behavior; and (3) we thought that CA/hypothalamopituitary interactions may be altered in unknown ways by use of a model involving unilateral lesions of ascending DA systems.

As predicted, we found sex differences in AMPH-elicited rotational behavior. Therefore, this behavior may be added to the list of non-reproductive behaviors which are scxually dimorphic. More interestingly, we found that these behavioral sex differences may be related to sex differences in the lateralization of striatal DA.

\section{METHOD}

\section{Subjects}

The experimental subjects were 26 female and 17 male adult Sprague-Dawley (Holtzman) rats $(200-325 \mathrm{~g})$ housed in a temperature $\left(23^{\circ} \mathrm{C}\right)$ and light controlled room $(14: 10 \mathrm{hr}$ light:dark cycle, lights off at 19:00 hr). The female group consisted of 14 rats which were in estrus and 12 rats which were in proestrus at the time of the experiment. Estrous cycle condition was determined by daily vaginal smear examinations for at least 8 days prior to the experiment, and only regularly cycling females were used. To control for the effects of handling the females, male rats were also handled daily prior to testing. The reason for examining females at known stages of their estrous cycle was to determine if this variable influenced rotational behavior. The effects of the estrous cycle on rotation will be discussed in a later publication.

\section{Apparatus}

The rats were tested in a spherical rotometer which consisted of 2 white hemispherical bowls with a diameter of 30.5 $\mathrm{cm}$, one inverted on the other. The top bowl had a $10 \mathrm{~cm}$ diameter hole in its top, which was covered with a wire grid through which the animal could be observed. The rotometer was divided into quadrants by lines on the outside of the top bowl.

\section{Procedure}

Testing occurred between 900 and 1200 hours. Each rat was individually placed in the rotometer and observed directly for $15 \mathrm{~min}$. A record was kept of every $1 / 4$ turn made to the right and left. A rat was considered to make a 1/4 turn whenever an imaginary point located midway between its front shoulders passed from one quadrant to another. The animal was then removed from the rotometer and injected with either $0.9 \%$ saline or d-amphetamine sulfate $(20 \mathrm{mg} / \mathrm{kg}$, IP) dissolved in saline $(20 \mathrm{mg} / \mathrm{ml})$. The animal was then immediately replaced in the rotometer and the above procedure repeated.

From the data on $1 / 4$ turns the following variables were calculated: (1) Total $1 / 4$ turns (1/4 turns to the left and right summed); (2) Total rotations (rotations to the left and right summed). One rotation equals 4 consecutive $1 / 4$ turns in the same direction; and (3) Net rotations (rotations in the dominant direction minus those to the other). This procedure was designed to produce data comparable to that obtained with the automatic rotometer described by Greenstein and Glick [31].

At the end of this second 15 min period, the animal was killed by decapitation and the brain placed on an ice-chilled tray. The striatum and medial frontal cortex [41] was then dissected from the brain by an experimenter (J. B. B.) who was unaware of the behavioral results. In all animals the order of dissection was (1) right striatum, (2) left striatum, (3) right medial frontal cortex, (4) left medial frontal cortex. The tissue pieces were weighed and placed in collection tubes on ice as each dissection was completed. After all pieces had been dissected, perchloric acid $(0.1 \mathrm{~N})$ was added to the collection tubes.

\section{Catecholamine Assay}

Tissue was homogenized in ice cold $0.1 \mathrm{~N} \quad \mathrm{HClO}_{4}$ (weight:volume, cortex 1:10; striatum 1:40) and centrifuged (Beckman J-21B centrifuge, JCF-2 swinging bucket rotor) at 5,000 RPM for $45 \mathrm{~min}$ at $4^{\circ} \mathrm{C}$. The supernatant was frozen at $-20^{\circ} \mathrm{C}$ until the day of the assay. Samples were assayed using a microradioenzymatic assay with a sensitivity of $32 \mathrm{pg}$ per tube [6]. In this assay, partially purified catechol-Omethyl-transferase (COMT) prepared from rat liver is used to transfer the methyl group of S-adenosyl-L-[methyl] ${ }^{3} \mathrm{H}$ methionine to norepinephrine and dopamine. After extraction of the methylated products, the $\mathrm{O}$-methylated $\left[{ }^{3} \mathrm{H}\right]$-normetanephrine and $\left[{ }^{3} \mathrm{H}\right]$-methoxytyramine are separated on Dowex-50-W-X-4 cation exchange columns and radioactivity in the appropriate effluent fractions determined by liquid scintillation [6].

\section{RESULTS}

\section{Behavior}

(A) Pre-Drug. In the initial $15 \mathrm{~min}$ period (prior to injection) female rats made significantly more total $1 / 4$ turns $(p<0.01)$ and total rotations $(p<0.02)$ than did males (Fig. $1 \mathrm{~A}$ and $1 \mathrm{~B}$, left). Unless otherwise noted, all comparisons were made with two-tailed t-tests.

Net rotations consist of total rotations in one direction minus total rotations in the other direction. An animal may be rotating very vigorously but if these rotations are distributed equally to the right and left, net rotations would equal zero. Thus, net rotations provide one index of behavioral lateralization. In the $15 \mathrm{~min}$ period prior to AMPH treatment females made a mean of $5.73 \pm 0.81$ (SE) and males $3.90 \pm 0.76$ net rotations (pre-drug in Fig. 1C). This difference was not statistically significant.

(B) Post-Drug. The effect of AMPH-treatment on total 1/4 turns and total rotations is plotted on Figs. $1 \mathrm{~A}$ and $\mathrm{B}$ (right). AMPH treatment greatly enhanced the number of $1 / 4$ turns (mean percent change \pm SE: males $-417 \pm 102 \%$; females $475 \pm 69 \%$ ) and total rotations (males-694 $\pm 217 \%$; females-872 $\pm 190 \%$ ) made by both males and females. After AMPH, females made significantly more total $1 / 4$ turns $(p<0.01)$ and total rotations $(p<0.05)$ than males. A saline injection produced no effect on rotational behavior, and activity decreased to very low levels as the animal further habituated to the apparatus. 

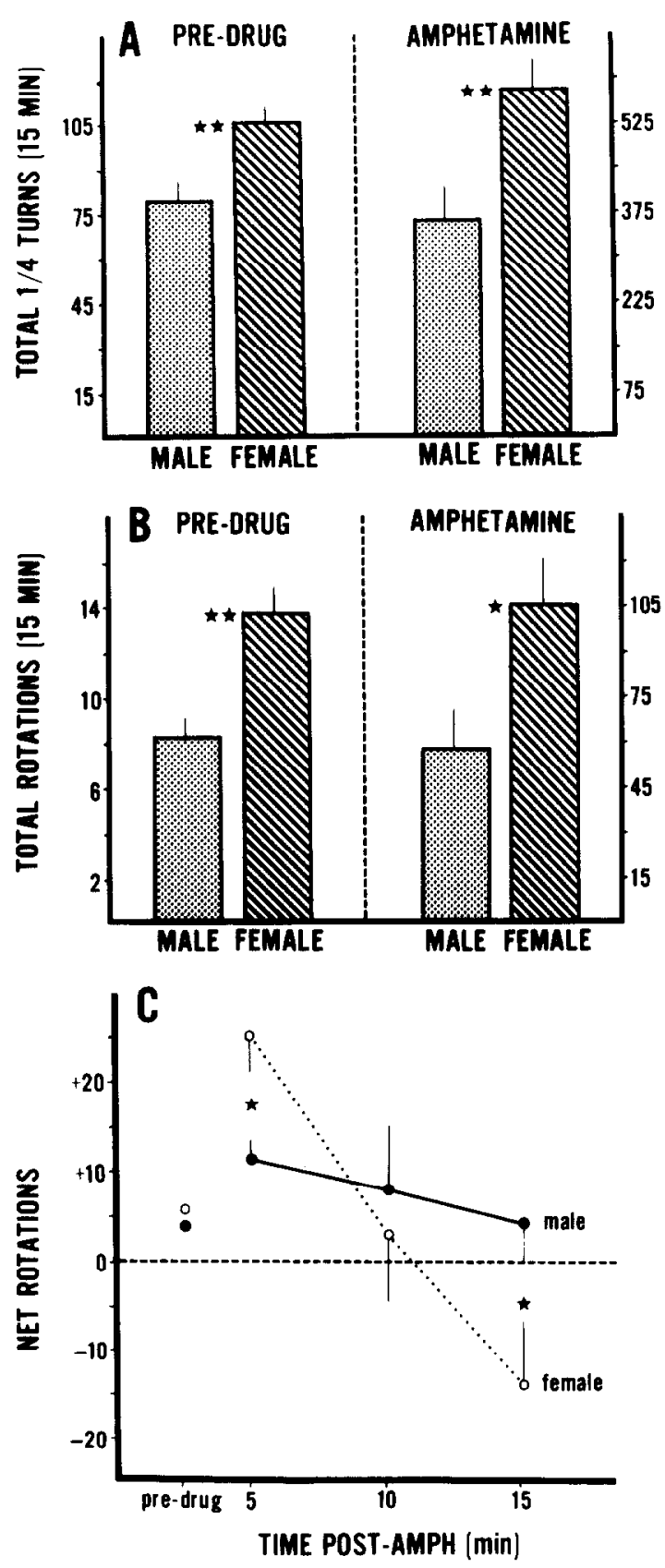

FIG. 1. Sex differences in rotational behavior prior to and after an injection of d-amphetamine (AMPH; $20 \mathrm{mg} / \mathrm{kg}$ ). (A) Total $1 / 4$ turns made by male and female rats during the $15 \mathrm{~min}$ period prior to AMPH (left), and during the 15 min period after AMPH treatment (right). Note the different scales pre- and post-AMPH. (B) Total rotations before (left) and after (right) AMPH treatment. (C) Net rotations. (i) The 2 pre-drug points represent total net rotations over the $15 \mathrm{~min}$ period prior to AMPH treatment. Pre-drug, net rotations to either the left or right are plotted as positive scores. (ii) During the first 5 min interval following AMPH some animals rotated predominantly left and others predominantly right. Whatever the dominant direction for an individual animal during the first 5 min interval, these net rotations were scored as a positive value. The net rotations plotted during the second and third 5 min intervals ( 10 and 15) were then scored relative to the first $5 \mathrm{~min}$ interval. Therefore, a negative value means that the animals were rotating in the opposite direction to which they rotated during the first 5 min interval. Bars ( $A$ and $B$ ) and circles $(C)$ represent mean values, and lines the standard error of the mean. $(* p<0.05 ; * * p<0.01)$.
The sex differences in net rotations made during the three 5 min intervals following AMPH were particularly striking (Fig. 1C). An analysis of variance revealed a significant main effect for time $(F=8.11, p<0.01)$ and a significant se $x \times$ time interaction $(\mathrm{F}=3.98, p<0.05)$, justifying pairwise comparisons (Duncan's procedure [61]). During the first 5 min interval following AMPH females made significantly more net rotations than the males did during any $5 \mathrm{~min}$ period $(p<0.05)$. Following the first $5 \mathrm{~min}$ interval sex differences in the pattern of rotations over time emerged. After exhibiting a significantly greater number of net rotations than males during the first $5 \mathrm{~min}$ interval the rotational behavior of the females declined significantly $(p<0.05)$, and during the second $5 \mathrm{~min}$ period they did not differ from males. This decline in net rotations was not due to a general decline in activity because the number of total rotations made by females actually increased from an average of $32.8 \pm 2.7$ (SE) during the first $5 \mathrm{~min}$ period to $43.1 \pm 8.9$ in the second $5 \mathrm{~min}$ period. During the third 5 min interval females significantly increased their net rotations again, and made more net rotations than males $(p<0.05)$. It is important to note, however, that the females reversed their direction of rotation between the first and third 5 min intervals. Thus, relative to males the net rotational behavior of the 'average' female was significantly elevated during the first $5 \mathrm{~min}$ interval following AMPH, it declined during the second 5 min period, and then was significantly elevated, but in the opposite direction, during the third 5 min interval.

In contrast to the females, neither the number nor direction of net rotations produced by the males differed significantly between the first, second or third 5 min intervals.

Finally, the extent of the change in the number of net rotations produced by AMPH appears to be greater in females than males. The average percent change in the number of net rotations when the last $5 \mathrm{~min}$ interval preAMPH is compared with the first 5 min interval post-AMPH is $1,795 \pm 421 \%$ (SE) for females and $850 \pm 189 \%$ for males ( $t=1.87, \mathrm{df}=23, p<0.072$ two tailed, $p<0.036$ one-tailed).

In summary, during the $15 \mathrm{~min}$ pre-drug period females made significantly more $1 / 4$ turns and total rotations than did males, but the sexes did not differ in the number of net rotations. AMPH greatly increased the number of total $1 / 4$ turns and total rotations made by both males and females, but the pre-drug sex difference persisted. In the first $5 \mathrm{~min}$ interval following AMPH the number of net rotations made by females increased to a greater extent than in males. Finally, the pattern of rotational behavior over time differed between females and males. During the last $5 \mathrm{~min}$ interval females rotated significantly more than males, but they reversed their direction of rotation relative to that in the first 5 min interval.

\section{Catecholamine Levels; Striatum}

Amphetamine-treated animals. Earlier studies have reported that following AMPH treatment, DA concentrations are higher in the striatum contralateral to the dominant direction of rotation [23]. However, in all the published experiments which have reported his asymmetry, of which we are aware, female rats were used. Therefore, we were anxious to compare the lateralization of striatal DA in relation to the differences in rotational behavior of male and female rats.

The calculation of CA levels in relation to the dominant 
TABLE

THE RELATIONSHIP OF STRIATAL AND NEOCORTICAL CATECHOLAMINE CONTENT TO ROTATIONAL BEHAVIOR IN AMPHETAMINE-TREATED MALE AND FEMALE RATS*

\begin{tabular}{|c|c|c|c|c|}
\hline & CONTRA. & IPSI. & Right & Left \\
\hline \multicolumn{5}{|l|}{ Striatal dopamine } \\
\hline Male $(n=10)$ & $11.77 \pm 1.38$ & $12.31 \pm 1.26$ & $13.19 \pm 1.14 \ddagger$ & $10.24 \pm 1.10$ \\
\hline Female $(n=14)$ & $14.17 \pm 1.02$ & $12.42 \pm 1.27$ & $14.12 \pm 1.128$ & $12.47 \pm 1.18$ \\
\hline \multicolumn{5}{|c|}{ Medial frontal cortex dopamine } \\
\hline Male $(n=10)$ & $0.057 \pm 0.009$ & $0.064 \pm 0.012$ & $0.064 \pm 0.01$ & $0.056 \pm 0.009$ \\
\hline Female $(n=12)$ & $0.074 \pm 0.010$ & $0.064 \pm 0.011$ & $0.062 \pm 0.008$ & $0.073 \pm 0.011$ \\
\hline \multicolumn{5}{|c|}{ Medial frontal cortex norepinephrine } \\
\hline Male $(n=9)$ & $0.132 \pm 0.019$ & $0.191 \pm 0.059$ & $0.139 \pm 0.018$ & $0.186 \pm 0.054$ \\
\hline Female $(n=14)$ & $0.122 \pm 0.015$ & $0.116 \pm 0.014$ & $0.116 \pm 0.014$ & $0.122 \pm 0.015$ \\
\hline
\end{tabular}

\footnotetext{
*Values represent mean levels $(\mathrm{ng} / \mathrm{mg}$ wet tissue weight) \pm standard error. $\mathrm{Ab}$ breviations: CONTRA. and IPSI. (contralateral and ipsilateral to the dominant direction of rotation observed during the first $5 \mathrm{~min}$ interval, respectively).

$\dagger$ Differs from female IPSI. DA $(t=2.19 ; p<0.05$; paired $t$-test; all tests two-tailed $)$.

末Differs from left male DA $(t=3.85 ; p<0.01)$.

$\$$ Differs from left female DA $(t=2.29 ; p<0.05)$.
}

direction of rotation was somewhat complicated by the fact that female rats changed their preferred direction of rotation over the three 5 min intervals, while the males did not (Fig. 1). However, previous studies by Glick et al. [24] suggest that with the dose of AMPH we used the direction of rotation observed in the first $5 \mathrm{~min}$ interval is the 'dominant direction of rotation.' In extensive AMPH dose-response studies Glick et al. [24] noted that after $20 \mathrm{mg} / \mathrm{kg}$ of AMPH peak rotational behavior occurs during the first $5 \mathrm{~min}$ interval. After lower doses of AMPH (e.g. $1.0 \mathrm{mg} / \mathrm{kg}$ ) peak rotational behavior is not observed until 30-40 min post-AMPH. Furthermore, the preferred direction of rotation seen during the first $5 \mathrm{~min}$ interval following $20 \mathrm{mg} / \mathrm{kg}$ AMPH is the same as the preferred direction observed if the same animal is given a low dose of AMPH at a different time [24]. Finally, following the first $5 \mathrm{~min}$ interval the direction of rotation becomes quite variable after large doses of AMPH [24]. Therefore, the dominant direction of rotation used in determining the relation of CA levels to behavior was that observed in the first 5 min interval following AMPH treatment.

Table 1 gives striatal DA levels in relation to the dominant direction of rotation. AMPH-treated female rats had significantly higher levels of DA in the striatum contralateral to the dominant direction of rotation, than in the ipsilateral striatum, as reported earlier by Glick and his colleagues [23]. However, to our surprise, males showed no significant relation between striatal DA levels and direction of rotation (Table 1). Of the $\mathbf{1 4}$ females tested, 12 had higher contralateral than ipsilateral striatal DA levels. Of the 11 males tested, 4 had higher contralateral levels, 5 had higher ipsilateral levels, 1 had equal contralateral/ipsilateral levels, and 1 did not show any net rotations.

Figure 2 shows the DA content of the striatum contralateral to the dominant direction of rotation, and the ipsilateral DA content expressed as a ratio (contralateral/ipsilateral or $\mathrm{C} / \mathrm{I}$ ratio). Thus, a $\mathrm{C} / \mathrm{I}$ ratio $>1$ indicates that $\mathrm{DA}$ levels were highest in the striatum contralateral to the dominant direction of rotation. Females treated with AMPH had more striatal $\mathrm{C} / \mathrm{I}$ ratios $>1$ than would be expected either by chance $\left(\chi^{2}=7.14, p<0.01\right)$, or than did AMPH-treated males
(Fisher test, $p<0.05$ ). In contrast, the $\mathrm{C} / \mathrm{I}$ ratios of $\mathrm{AMPH}$ treated males did not differ from chance in either direction.

Of the 14 females tested, 10 rotated preferentially to the left. This seeming preference for the left is probably due to chance since Glick and his colleagues have tested many females and report that preferences for the left and right are evenly distributed in a large sample [24]. However, the distribution of rotational preferences in our sample of animals resulted in 10/14 females having the striatum on the right side contralateral to the preferred direction of rotation. This probably explains why the right striatum of females had significantly higher DA levels than the left striatum (Table 1). Of the 4 females which rotated preferentailly to the right, 3 of these had higher left than right striatal DA levels, and one higher right DA.

A totally unexpected finding shown in Table 1 is that although AMPH treated males showed no relationship between direction of rotation and striatal DA they nevertheless had an asymmetry in striatal DA levels which was unrelated to behavior. In AMPH treated males the levels of DA in the right striatum were significantly higher than those in the left. The distribution of rotational preferences cannot account for this latter finding since 5 of the males rotated predominantly right, 5 predominantly left, and 1 showed no net rotations. The possibility that this asymmetry was due to a bias in the dissection procedure, which resulted in more tissue being excised on the right then the left was examined, but the average wet tissue weights showed no left-right differences. Moreover, if this asymmetry were due to the order of dissection similar asymmetries might be expected in the salinetreated animals or in cortical CA levels, but none were found. Since this is the first report of a left-right asymmetry in striatal DA these observations need to be replicated.

Saline-treated animals and medial frontal cortex $C A$ levels. As noted above, no asymmetry was found in striatal DA levels in relation to rotational behavior or between the left and right striatum, in either males or females treated with saline (Fig. 2). Glick et al. $[23,24]$ have reported similar results for females. However, interesting differences emerged when striatal DA levels were compared between saline and 


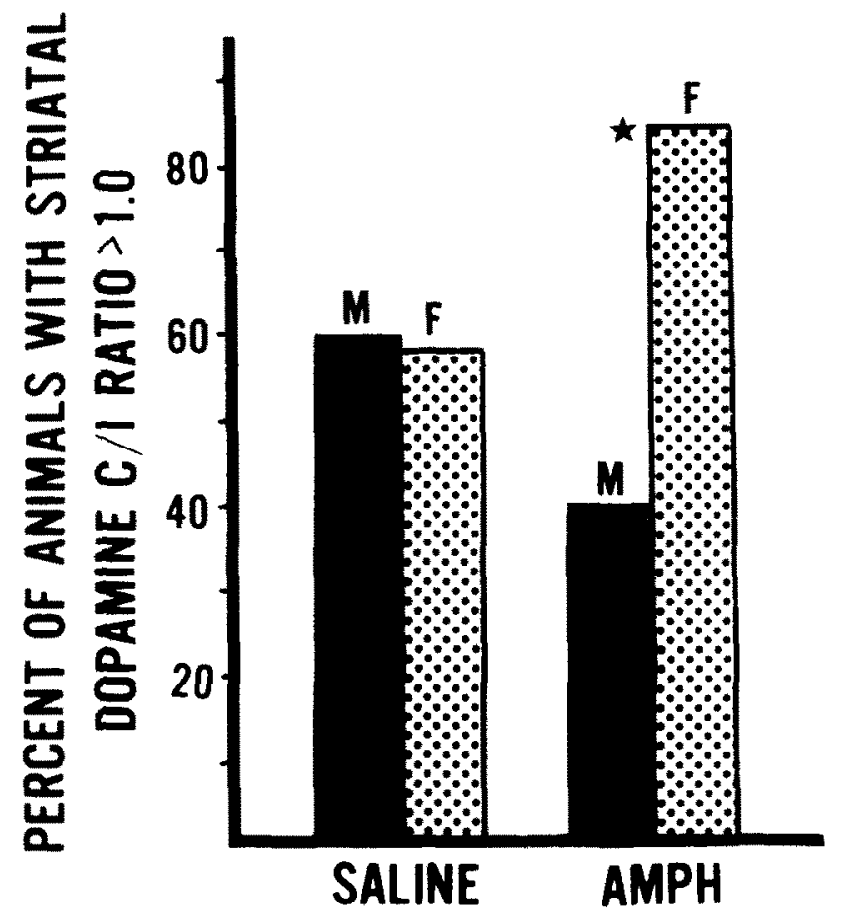

FIG. 2. The relationship of striatal dopamine (DA) content to rotational behavior in amphetamine (AMPH) or saline-treated male and female rats. For this analysis the DA content of the striatum located contralateral to the dominant direction of rotation, and the DA content of the striatum located ipsilateral to the dominant direction of rotation were expressed as a ratio ( $\mathrm{C} / \mathrm{I}$ ratio). $\mathrm{A} \mathrm{C} / \mathrm{I}$ ratio $>1$ indicates that DA levels were highest in the striatum contralateral to the dominant direction of rotation. For saline-treated animals the dominant direction of rotation was calculated over the first $15 \mathrm{~min}$. A little over half of the male and female saline-treated rats had $\mathrm{C} / \mathrm{I}$ ratios $>1$, and this was not significantly above what would be cxpected by chance for either group. For AMPH treated animals, C/I striatal DA ratios were calculated relative to the dominant direction of rotation during the first $5 \mathrm{~min}$ interval post-AMPH (see text). After AMPH, males did not show any significant relationship between direction of rotation and striatal DA. Females had significantly more C/I striatal DA ratios $>1$ than males, or would be expected by chance.

AMPH-treated animals. Relative to levels in saline-treated female animals, AMPH treated female rats had elevated DA levels in the striatum contralateral to the dominant direction of rotation $(p<0.01)$. This was not true for males. Since the majority of females rotated predominantly to the left, it would be expected that elevated DA levels would also be found in the right striatum of AMPH treated females, relative to saline controls, and indeed they were $(p<0.05)$. The higher DA levels found in the right striatum of males, relative to the left, were also accompanied by a significant elevation of right striatal DA in AMPH-treated males, relative to saline-treated males $(p<0.05)$.

Examination of medial frontal cortex DA and NE levels did not reveal any striking asymmetries, such as those seen in striatal DA (Table 1). There were no significant differences in CA levels when contralateral-ipsilateral or right-left values were compared, regardless of sex or treatment.

\section{DISCUSSION}

Glick and his colleagues originally reported that AMPH produces rotational behavior in unlesioned female rats [35], and that the striatum with the highest DA content is usually contralateral to the dominant direction of rotation [23]. The experiments reported here support these contentions, but in addition, we report sex differences both in rotational behavior and in the lateralization of striatal DA. After AMPH, female rats showed significantly greater rotational behavior than males. Biochemical analyses showed that in AMPH treated females the preferred direction of rotation was contralateral to the striatum with the highest DA content. This asymmetry appears to be confined to striatal DA as no relationship was found between rotational behavior and medial frontal cortex DA or NE. In addition, Glick et al. [24] reported no relationship between rotational behavior and striatal acetylcholine $(\mathrm{ACh})$ or telendiencephalic $\mathrm{ACh}$ or NE in female rats. Male rats differed from females in that, (1) they rotated less than females, and (2) no relationship was found between the preferred direction of rotation and the lateralization of striatal DA in males. However, AMPH treated male rats did have significantly higher DA in the right than in the left striatum, irrespective of rotational behavior. This surprising finding needs to be replicated. Thus, the evidence suggests that the striatum of both males and females are asymmetrically organized, but in different ways. The female striatum may be organized asymmetrically in relation to rotational behavior, while the male striatum is not. This suggestion is supported by Glick's comment [25] that female gerbils show greater net rotations and percent dominance scores than males.

Males and females also differed in the pattern of rotations over time. In the last 5 min interval, females, but not males, rotated in the opposite direction to the first 5 min interval. Glick et al. [24] previously noted that during the last $30 \mathrm{~min}$ of a test session female rats given a large dose of AMPH tend to reverse their usual rotational preference. One possible explanation for this reversal may be that AMPH elicits a massive release of $D A$, which initially is greater in the striatum contralateral to the direction of rotation in females. This greater release may then result in the feedback inhibition of release and/or DA synthesis, perhaps mediated by pre-synaptic DA receptors $[10,56]$. Greater inhihition of the side contralateral to the initial direction of rotation would result in predominant release ipsilateral and therefore a reversal in the direction of rotation. The decline in net rotations during the second 5 min interval may reflect a period of transition.

It is possible that the results reported here are due to sex differences or asymmetries in the metabolism of AMPH. However, AMPH is reported to reach each striatum in equal quantities when injected systemically [24]. Therefore, the asymmetries in striatal DA content induced by $A M P H$ are probably not due to the asymmetric uptake of AMPH. Sex differences have been described in AMPH metabolism $[32,47]$, and this factor needs to be examined more closely. Although Meyer and Lytle [47] reported that female rats accumulate more AMPH in the brain than males at $30 \mathrm{~min}$ to several hours post-injection, they found no sex difference at $5 \mathrm{~min}$, which is when we see the largest behavioral differences. In addition, sex differences have been reported in AMPH-stimulated DA release from striatal tissue fragments in vitro [5]. It is very unlikely that this in vitro response of striatal tissue fragments could be due to sex differences in the metabolism of AMPH.

Another possibility is that the sex differences in AMPHinduced rotational behavior reported here are due to sex 
differences in the modulation of striatal DA activity by gonadal steroid hormones. In female rats ovariectomy (OVX) severely attenuates the AMPH-stimulated release of DA from striatal tissue fragments in vitro [5]. The in vivo administration of estrogen plus progesterone reinstates the in vitro release of DA in OVX females (J. B. Becker, unpublished data). In contrast, castration has no effect on the in vitro release of DA from striatal tissue fragments obtained from male rats [5].

There appears to be growing support for the idea that gonadal steroids modulate striatal activity. However, the nature of the interaction is far from clear. It has been suggested that some female gonadal steroids may have an antidopaminergic effect on striatal activity [7]. This is supported by reports that estrogen treatment dccreases circling behavior induced by apomorphine (APO) in unilaterallylesioned rats [7]. Reports that estradiol or progesterone attenuate stereotyped behaviors induced by AMPH or $\beta$-phenylethylamine (PEA) [50], that ovariectomy (OVX) enhances PEA-elicited stereotyped behaviors [50], that estrogen prolongs spiperone-induced catalepsy [11], and that estrogen reduces the increases in striatal $\mathrm{ACh}$ normally induced by DA agonists [19], all support this idea. Female rats have also been reported to show a higher incidence of chlorpromazine-induced catalepsy than males, and this sex difference is abolished by OVX [48].

In contrast, there is evidence which suggests that female gonadal steroids may enhance striatal dopaminergic activity. In addition to the results reported here, others have reported that estrogen prolongs the duration and increases the intensity of AMPH or APO elicited rotational and stereotyped behaviors $[33,39]$. In female guinea pigs, OVX decreases the responsiveness to AMPH or APO [51]. Also, females are reported to show longer and more intense stereotyped behavior after AMPH than males $[4,20]$. These findings may relate to reports that estrogen increases the amount of $\left[{ }^{3} \mathrm{H}\right]$ spiroperidol binding in striatum $[16,33]$, and that $\mathrm{OVX}$ reduces DA-stimulated adenylate cyclase activity in the striatum and nucleus accumbens [38]. Further research may reveal that many of these discrepancies are due to species, sex and drug dosage level differences between the various studies.

The idea of sex differences in striatal function does have clinical relevance and may relate to reports that human females show a greater incidence of extra-pyramidal side effects following treatment with neuroleptic drugs than do males $([1,12,21,40]$; however, also see [13]). In addition, choreiform disorders are sometimes associated with preg. nancy (chorea gravidarum) $[17,62]$, and as a complication of oral contraceptives [17]. Gonadal steroid modulation of striatal activity may have therapeutic relevance since it is reported that estrogen may precipitate Parkinsonian symptoms in males or females receiving neuroleptics [29], but improves the symptoms of tardive dyskinesia [8].

Lastly, the greater amount of lateralized behavior in female rats reported here may relate to reports that female children show greater motor asymmetries than males $[36,46]$. Girls are reported to show greater preferences for their right hand than boys. However, this latter sex difference may not persist into adulthood [46]. In contrast, adult human females are reported to be less lateralized than males both anatomically [60], and in verbal and visuo-spatial abilities $[44,45,46]$. Regardless of the direction, sex differences in brain lateralization in humans and rats may have a common developmental basis. The sex differences may result from anatomical differences which occur during early sexual differentiation and/or the hormonal changes of puberty. Whatever the answers to these questions, it seems apparent that there may be greater differences between the brains of males and females than previously thought.

\section{REFERENCES}

1. Ayd, F. J., Jr. Neuroleptics and extrapyramidal reactions in psychiatric patients. In: Extrapyramidal System and Neuroleptics, edited by J. M. Bordeleau. Montreal: Editions Psychiatriques, 1961, pp. 355-363.

2. Reatty, W. W. Effects of gonadectomy on sex differences in DRL behavior. Physiol. Behav, 10: 177-178, 1973.

3. Beatty, W. W. Gonadal hormones and sex differences in nonreproductive behaviors in rodents: organizational and activational influences. Hormones Behav, 12: 112-163, 1979.

4. Beatty, W. W. and G. A. Holzer. Sex differences in stereotyped behavior in the rat. Pharmac. Biochem. Behav. 9; 777-783, 1978 .

5. Becker, J. B. and V. D. Ramirez. Sex differences in the amphetamine stimulated release of endogenous catecholamines in vitro. Soc. Neurosci. Abstr. 5: 438, 1979.

6. Becker, J. B. and V. D. Ramirez. Dynamics of endogenous catecholamine release from brain fragments of male and female rats. Neuroendocrinology 31: 18-25, 1980.

7. Bedard, P., J. Dankova, R. Boucher and P. Langelier. Effect of estrogen on apomorphine-induced circling behavior in the rat. Can. J. Physiol. Pharmac. 56: 538-541, 1978.

8. Bedard, P., P. Langelier and A. Villeneuve. Oestrogens and extrapyramidal system. Lancet II: 1367-1368, 1977.

9. Braggio, J. T., R. D. Nadler, J. Lance and D. Miseyko. Sex differences in apes and children. In: Recent Adrances in Primatology, Behavior, Vol. I, edited by D. J. Chivers and J. Herbert. New York: Academic, 1978, pp. 529-531.
10. Bunney, B. S. and G. K. Aghajanian. Evidence for drug actions on both pre- and postsynaptic catecholamine receptors in the CNS. In: Pre- and Postsynaptic Receptors, edited by E. Usdin and W. E. Bunney, Jr. New York: Dekker, 1975, pp. 89-120.

11. Chiodo, L. A., A. R. Caggiula and C. F. Saller. Estrogen increases both spiperone-induced catalepsy and brain levels of [ $\left.{ }^{3} \mathrm{H}\right]$ spiperone in the rat. Brain Res. 172: 360-366, 1979.

12. Crane, G. E. Tardive dyskinesia in patients treated with major neuroleptics. A review of the literature. Am. J. Psychiat. 124: 40-48 (Suppl), 1968.

13. Crane, G. E. Factors predisposing to drug-induced neurologic effects. In: The Phenothiazines and Structurally Related Drugs, edited by I. S. Forrest, C. J. Carr and E. Usdin. New York: Raven, 1974, pp. 269-279.

14. Crowley, W. R., T. L. O'Donahue and D. M. Jacobowitz. Gonadal hormone-catecholamine interactions in discrete regions of the central nervous system. Soc. Neurosci. Abstr. 3: $342,1977$.

15. Crowley, W. R., T. L. O'Donahue and D. M. Jacobowitz. Changes in catecholamine content in discrete brain nuclei during the estrous cycle of the rat. Brain Res. 147: 315-326, 1978.

16. DiPaolo, T., F. Labrie, A. Dupont, N. Barden and P. Langelier. Effects of estrogen treatment on normal and sensitized rat striatal dopamine (DA) receptors and DA-sensitive adenylyl cyclase. Soc. Neurosci. Abstr. 5; 443, 1979.

17. Donaldson, J. O. Neurology of Pregnancy. Philadelphia: W. B. Saunders, 1978. 
18. Dörner, G. and J. Staudt. Perinatal structural sex differentiation of the hypothalamus in rats. Neuroendocrinology 5: 103-106, 1969.

19. Euvrard, C., F. Labrie and J. R. Boissier. Effect of estrogen on changes in the activity of striatal cholinergic neurons induced by DA drugs. Brain Res. 169: 215-220, 1979.

20. Flemenbaum, A. Rat dopaminergic hypersensitivity. 11. Effects of sex. Neuropsychobiology 5: 222, 1979.

21. Freyhan, F, A. Psychomotility and Parkinsonism in treatment with neuroleptic drugs. Archs Neurol. Psychiat, 78: 465-472, 1957.

22. Fuxe, K., T. Hokfelt, A. Lofstrom, O. Johansson, L. Agnati, B. Everett, M. Goldstein, S. Jeffcoate, N. White, P. Everoth, J. A. Gustafsson and $P$. Shett. On the role of neurotransmitters and hypothalamic hormones and their interactions in hypothalamic and extrahypothalamic control of pituitary function and sexual behavior. In: Subcellular Mechanisms in Reproductive Neuroendocrinology, edited by F. Naftolin, K. J. Ryan and I. J. Davies. Amsterdam: Elsevier, 1976. p. 193.

23. Glick, S. D., T. P. Jerussi, D. H. Waters and J. P. Green. Amphetamine-induced changes in striatal dopamine and acetylcholine levels and relationship to rotution (circling behavior) in rats. Biochem. Pharmac. 23: 3223-3225, 1974.

24. Glick, S. D., T. P. Jerussi and B. Zimmerberg. Behavioral and neuropharmacological correlates of nigrostriatal asymmetry in rats. In: Lateralization in the Nervous System, edited by S. Harnad, et al. New York: Academic Press, 1977, pp. 213-249.

25. Glick, S. D., B. Zimmerberg and T. P. Jerussi. Adaptive significance of laterality in the rodent. Ann. N.Y. Acad. Sci. 299: $180-185,1977$.

26. Gorski, R. A., J. H. Gordon, J. E. Shryne and A. M. Southam. Evidence for a morphological sex difference within the medial preoptic area of the rat brain. Brain Res. 148: 333-346, 1978.

27. Goy, R. W. and B. S. McEwen. Sexual Differentiation of the Brain. Cambridge, Mass.: MIT Press, 1980.

28. Goy, R. W. and C. H. Phoenix. The effects of testosterone propionate administered before birth on the development of behavior in genetic female rhesus monkeys. In: Steroid Hormones and Brain Function, edited by C. H. Sawyer and R. A. Gorski. Berkeley: Univ. Cal. Press, 1971, pp. 193-200.

29. Gratton, L. Neuroleptiques, parkinsonisme et schizophrenie. Union Med. Can. 89: 681-694, 1960.

30. Greenough, W, C. Carter, C. Steerman and T. DeVoogd. Sex differences in dendritic patterns in hamster preoptic area. Brain Res. 126: 63-72, 1977.

31. Greenstein, S. and S. D. Glick. Improved automated apparatus for recording rotation (circling behavior) in rats or mice. Pharmac. Biochem. Behav. 3: 507-510, 1975.

32. Groppetti, $A$ and E. Costa. Factors affecting the rate of disappearance of amphetamine in rats. Int. $I$. Neuropharmac, 8: 209-215, 1969.

33. Hruska, R. E. and E. K. Sibergeld. Increased dopamine receptor sensitivity after estrogen treatment. Soc. Nourosci, Abstr. 5: $73,1979$.

34. Jori, A., F, Colturani, E. Dolfini and M. Rutczynski. Modifications of the striatal dopamine metabolism during the estrous cycle in mice. Neuroendocrinology 21: 262-266, 1976.

35. Jerussi, T. P. and S. D. Glick. Amphetamine-induced rotation in rats without lesions. Neuropharmacology 13: 283-286, 1974.

36. Jones, H. Sex differences in physical abilities, Human Biol. 19: $12-25,1947$

37. Krecek, J., V. Novakova and K. Stibral. Sex differences in the taste preference for a salt solution in rat. Physiol. Behav. 8: 183-188, 1972.

38. Kumakura, K., M. Hoffman, D. Cocchi, M. Travucchi, P. F. Spano and E. E. Muller. Long term effect of ovariectomy on dopamine-stimulated adenylate cyclase in rat striatum and nucleus accumbens, Psychopharmacology 61: 13-16, 1979.

39. Lal, S. and Th. L. Sourkes. Potentiation and inhibition of the amphetamine stereotypy in rats by neuroleptics and other agents. Archs int. Pharmacodyn. 199: 289-301, 1972.
40. Lehmann, H. E. and T. A. Ban. Sex differences in long-term adverse effects of phenothiazines. In: The Phenothiazines and Structurally Related Drugs, edited by I. S. Forrest, C. J. Carr and E. Usdin. New York: Raven, 1974, pp. 249-254.

41. Leonard, C. M. The prefrontal cortex of the rat. 1. Cortical projections of the mediodorsal nucleus. II. Efferent connections. Brain Res. 12: 321-343, 1969.

42. Levine, S. and P. L. Broadhurst. Genetic and ontogenetic determinants of adult behavior in the rat. J. comp. physiol. Psychol. 56: 423-428, 1963.

43. Maccoby, E. E. and C. N. Jacklin. The Psychology of Sex Differences. Stanford: Stanford University Press, 1974.

44. McGlone, J. Sex differences in the cerebral organization of verbal functions in patients with unilateral brain lesions. Brain 100: $775-793,1977$.

45. McGlone, J. Sex differences in functional hrain asymmetry. Cortex 14: 122-128, 1978.

46. McGlone, J. Sex differences in human brain organization: a critical review. Univ. West. Ont. Res. Bull. \#399, 1979.

47. Meyer, E. M. Jr, and L. D. Lytle. Sex related differences in the physiological disposition of amphetamine and its metabolites in the rat. Proc. West. Phurmuc. Soc. 21: 313-316, 1978.

48. Mislow, J. F, and A. J. Friedhoff. A comparison of chlorpromazine-induced extrapyramidal syndrome in male and female rats. In: Hormones and Brain Function, edited by $\mathbf{K}$. Lissak. New York: Plenum, 1973, pp. 315-326.

49. Moore, K. E. and P. H. Kelly. Biochemical pharmacology of mesolimbic and mesocortical dopaminergic neurons. In: $P s y-$ chopharmacology: A Generation of Progress, edited by M. A. Lipton, A. DiMascio and K. F. Killam. New York: Academic, 1978, pp. 221-234.

50. Naik, S. R., M. R. Kelkan and U. K. Sheth. Attenuation of stereotyped behavior by sex steroids. Psychopharmacology 57: $211-214,1978$.

51. Nausieda, P. A., W. C. Koller, W. J. Weiner and H. L. Klawans. Modification of post-synaptic dopaminergic sensitivity by female sex hormones. Life Sct: 25: 521-526, 1979.

52. Nottebohm, F. and A. P. Amold. Sexual dimorphism in vocal control areas of the songbird brain. Science 194: 211-213, 1976.

53. Olioff, M. and J. Stewart. Sex differences in play behavior of prepubescent rats. Physiol. Behav. 20: 113-115, 1978.

54. Raisman, G. and P. Field. Sexual dimorphism in the neuropil of the preoptic area of the rat and its dependence on neonatal androgen, Brain Res. 54: 1-29, 1973 .

55. Reinisch, J. M. Fetal hormones, the brain and human sex differences: a heuristic, integrative review of the recent literature. Archs Sex. Behav. 3: 51-90, 1974.

56. Roth, R. H., J. R. Walters, L. C. Murrin and V. H. Morgenroth, III. Dopamine neurons: role of impulse flow and pre-synaptic receptors in the regulation of tyrosine hydroxylese. In: Pre- and Postsynaptic Receptors, edited by E. Usdin and W. E. Bunney, Jr. New York: Dekker, 1975, pp. 5-46.

57. Tryon, R. C. Studies in individual differences in maze ability: II The determination of individual differences by age, weight, sex and pigmentation. J. comp. Psychol. 12: 1-22, 1931.

58. Ungerstedt, U. Functional dynamics of central monoamine pathways. In: The Neurosciences: Third Study Program, edited by $F$. $O$. Schmitt and $F$. G. Worden. Cambridge, Mass.: MIT Press, 1974, pp. 979-988.

59. Valenstein, E. $S_{*}$ J. W. Kakolewski and V. C. Cox. Sex differences in taste preference for glucose and saccharin solutions. Science 156: 942-943, 1967.

60. Wada, J. A., R. Clarke and A. Hamm. Cerebral hemispheric asymmetry in humans. Archs Neurol. 32: 239-246, 1975.

61. Winer, B. J. Statistical Principles in Experimental Design. New York: McGraw-Hill, 1971.

62. Zegart, K. H. and R. H. Schwartz. Chorea gravidarum. Obstetrics and Gynecol, 32: 24-27, 1968. 